\title{
TAX CUTS AND EMPLOYMENT GROWTH IN NEW JERSEY: \\ LESSONS FROM A REGIONAL ANALYSIS
}

\author{
W. ROBERT REED \\ CYNTHIA L. ROGERS \\ University of Oklahoma
}

\begin{abstract}
The Whitman administration's $30 \%$ reduction in New Jersey's personal income taxes from 1994 to 1996 is prominently cited as a role model for state fiscal policy. The authors investigate whether the growth benefits attributed to the Whitman tax cuts are warranted. Panel data methods are applied to annual observations of county-level employment growth from New Jersey and the surrounding economic region. This study's analysis does not support the hypothesis that tax cuts stimulated employment growth in New Jersey. Although New Jersey did experience substantial employment growth subsequent to the tax cuts, most of this growth was shared by the nearby Economic Areas.
\end{abstract}

Keywords: income tax; tax cuts; state fiscal policy; New Jersey; employment growth

State fiscal policy follows a distinct cyclical pattern. Although tax increases are a typical response to budget shortfalls (often required by balanced budget legislation), tax cuts are offered as an economic stimulant. Academic research, however, offers little guidance regarding such tax policy decisions.

Economic theory offers a range of models regarding the growth impacts of changes in state fiscal policy. Tax cuts could stimulate eco-

AUTHORS' NOTE: Richard L. Kaluzny, Chief of the Office of Tax Analysis, Department of Treasury of the State of New Jersey, was of great assistance in providing information about tax cuts during the Whitman administration. Kevin Grier, Timothy Dunne, Stephen Ellis, and Stephan Weiler offered insightful questions and comments that contributed to improvements in our analysis. This research was financially supported by the Oklahoma Office of State Finance. In addition, the staff of the Oklahoma Office of State Finance provided insightful feedback at numerous junctures. We are indebted to all these individuals for their valuable assistance. The opinions and conclusions stated in this article are exclusively those of the authors and are not necessarily endorsed by the individuals above or the Oklahoma Office of State Finance.

PUBLIC FINANCE REVIEW, Vol. 32 No. 3, May 2004 269-291

DOI: $10.1177 / 1091142104264488$

(C) 2004 Sage Publications 
nomic growth by altering incentives to save, invest, and participate in the workforce. Tax cuts, however, may be coupled with changes in expenditures. Both the distortionary nature of the tax scheme, as well as the productive nature of public spending, affect overall growth outcomes. In addition, tax-mimicking behavior can mitigate the potential stimulative effects of reducing a state's tax burden (Besley and Case 1995; Case 1993). Of course, if state economic growth is exogenous, then tax policy changes will not affect long-run economic growth.

The empirical literature does not clarify the relationship between state tax policy changes and economic growth. ${ }^{1}$ Some surveys suggest that state tax cuts have a positive, but very modest, impact on economic development (Bartik 1991; Phillips and Gross 1995; Wasylenko 1997). Several prominent studies conclude that state tax cuts paid for by reduced spending on public services - as opposed to transfer payments - have a negative impact on economic development (Helms 1985; Mofidi and Stone 1990; Bartik 1991; Tannenwald 1996; Lynch 1996). ${ }^{2}$ To the extent a consensus exists, it is that previous results should be viewed as unreliable and uncertain. ${ }^{3}$

Several estimation problems, including misspecification, measurement error of key policy variables, and endogeneity of tax changes, contribute to the unreliability of the academic literature (Carroll and Wasylenko 1994; Phillips and Gross 1995; Becsi 1996). Endogeneity arises because states tend to raise (lower) taxes in poor (good) economic times. To resolve the inherent estimation problems, Poot (2000) and others have called for studies that "rely on natural "experiments' —studies that observe how similar local economies ... respond to large, exogenous changes in tax regimes" (Bartik 1997, 68).

Notably, the promoters of tax-cutting policies base their recommendations primarily on individual state experiences. A prominently mentioned "role model" is the New Jersey experience under the leadership of Governor Christine Todd Whitman (Garfield 1996; Moore and Stansel 1996). Whitman spearheaded a cumulative 30\% reduction in state personal income tax from 1994 to 1996. Reviewing state tax changes since the late 1960s, we conclude that New Jersey offers a rare case of a tax-cutting policy resembling a "natural experiment" with a large, exogenous tax cut. ${ }^{4}$ 
Our study investigates whether the growth benefits attributed to the Whitman tax cuts are warranted. Unlike typical studies of state tax impacts, our analysis applies panel data methods to county-level (rather than state-level) data for New Jersey and the surrounding economic region. ${ }^{5}$ Following an event study format, impacts are measured using annual observations of employment growth before and after the respective tax cuts. Our results suggest that undue credit is attributed to the Whitman tax cuts. Although New Jersey did experience substantial growth in the time period coinciding with the tax cuts, the adjoining region shared most of this growth. The residual growth specific to New Jersey is not statistically significant.

\section{BACKGROUND ON THE 1994-1996 NEW JERSEY TAX CUTS}

The recession of the early 1990s resulted in significant state tax increases across the country. As the economy was beginning to recover from the recession, tax relief, fiscal responsibility, and smaller government were common themes in the campaign platforms. The ubiquity of voter discontent was evident from the 1994 national elections results. In Congress, voters elected a Republican majority to the House of Representatives for the first time since 1953. Of the 36 gubernatorial elections, there were 16 changes in the political affiliations of the elected governors. ${ }^{6}$ Twelve of the changes, including New York, Pennsylvania, and New Jersey, went from Democratic to Republican.

The implementation of the New Jersey tax cuts under Whitman was unique even for a new governor. ${ }^{7}$ Whitman distinguished herself by publicly announcing a very specific, tax-cutting plan long before she was elected to office. In her 1993 gubernatorial campaign, Whitman heavily emphasized her ambitious plan to reduce personal income taxes across the board by $10 \%$ each of her first 3 years in office. ${ }^{8}$ Not driven by budget surpluses, Whitman's tax plan was widely criticized by those who feared it would lead to massive deficits (Mullaney 1994). Subsequent to being elected, Governor Whitman immediately moved to have her tax plan implemented as promised. Whitman is 
TABLE 1: Summary of Nature and Estimated Size of Tax Changes: New Jersey, 1994-1996

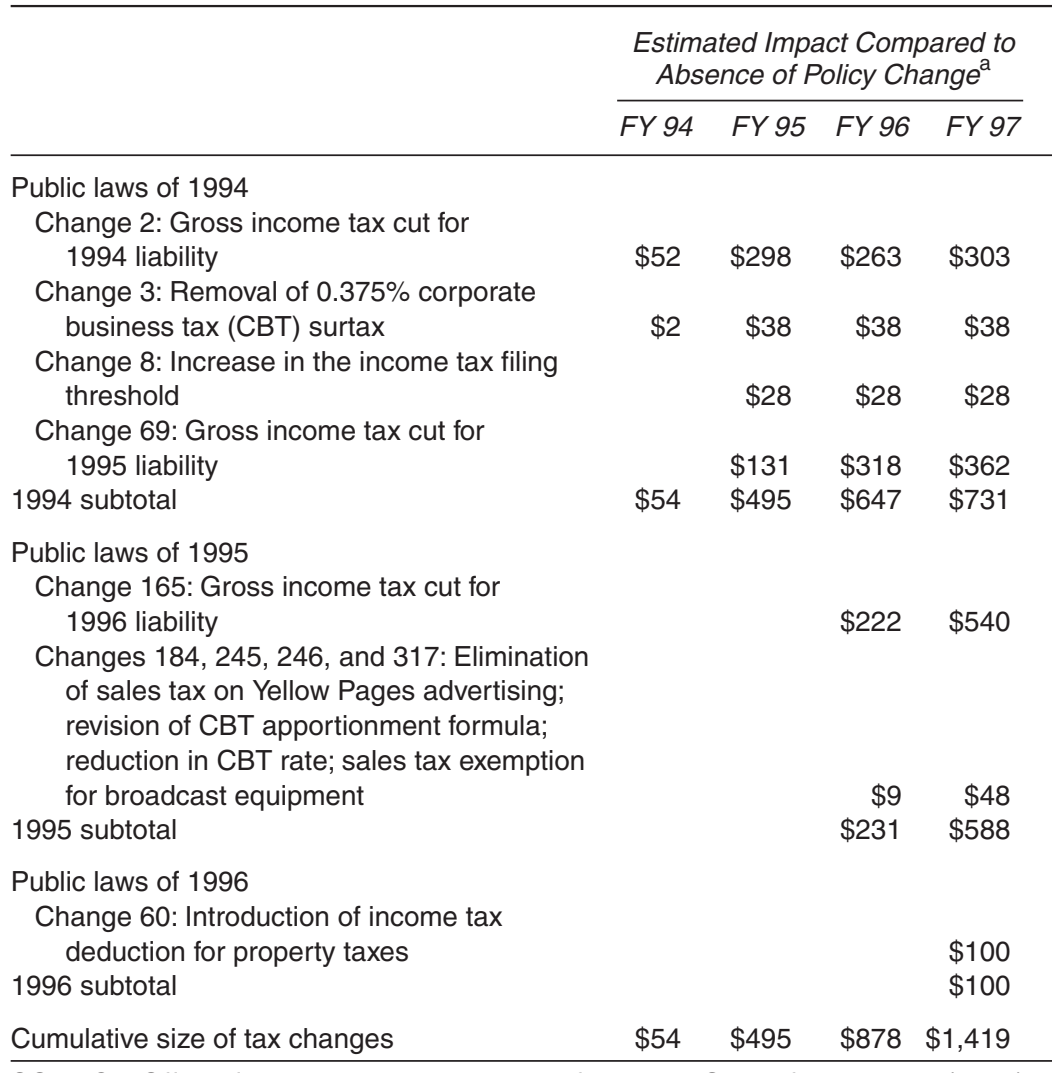

SOURCE: Office of Tax Analysis, Department of Treasury, State of New Jersey (1998). a. The unit of measurement for the estimated impacts is millions of dollars.

widely credited with being the primary political orchestrator of the New Jersey tax cuts.

The Whitman tax cuts represent a significant departure from the tax regimes of the other states in the Mideast region faced with similar economic forces. ${ }^{9}$ As confirmed in Table 1, New Jersey's tax cuts came primarily from reductions in the personal income tax. The result of the New Jersey tax cuts was a cumulative, $30 \%$ reduction in New Jersey's personal income tax for most state residents, phased in over a 3-year period from 1994 to 1996. The other states in the Mideast re- 
gion also enacted some reductions in personal and corporate income taxes from 1994 to $1997 .{ }^{10}$ As Gold (1996) emphasizes, however, measuring the size of tax changes is notoriously difficult. This makes cross-state comparisons problematic.

Table 2 reports the National Conference of State Legislatures (NCSL) estimates of revenue impacts among the Mideast region states using two alternative accounting methods: the baseline and the tax liability methods. The middle section of Table 2 uses the NCSL baseline method to calculate revenue impacts relevant for the calendar years 1989-1997. The left-hand side of the table reports the fiscal year in which the tax changes were enacted. By this measure, the Jersey tax cuts appear to be significantly larger than the cuts in the other states in the region. ${ }^{11}$ Furthermore, New Jersey is the only state to have enacted "major" tax changes in 3 consecutive years. ${ }^{12}$

The baseline estimates, however, are subject to criticism. Under this method, changes are measured against the obligation that would have existed had no tax action been taken. Thus, if a scheduled tax reduction were postponed through legislative action, it would count as a tax increase even though the effective tax liability did not change from the previous year. From 1990 through 1994, New York postponed reductions in personal income taxes that had been scheduled to occur in previous legislation. According to the baseline (but not the tax liability) method, these postponements are counted as tax increases. In addition, the baseline method only measures changes in the first fiscal year for which the legislation is implemented, understating the effect of multiyear tax cut legislation. Both New Jersey and New York had multiyear tax cut legislation during the period.

The lower section of Table 2 uses the tax liability method to calculate revenue impacts for the calendar years $1994-1997 .{ }^{13}$ The left-hand side of the table reports the fiscal years during which the tax changes had their impact, as opposed to when the tax legislation was enacted. Using this method, it appears that both New Jersey and New York enacted significant tax cuts during the 1994-1997 fiscal year period. The big difference between New Jersey and New York lies in the timing of their respective tax cuts. The Whitman tax cuts were concentrated in the beginning of the 1994-1997 period, whereas the New York tax cuts were concentrated at the end of this period. 


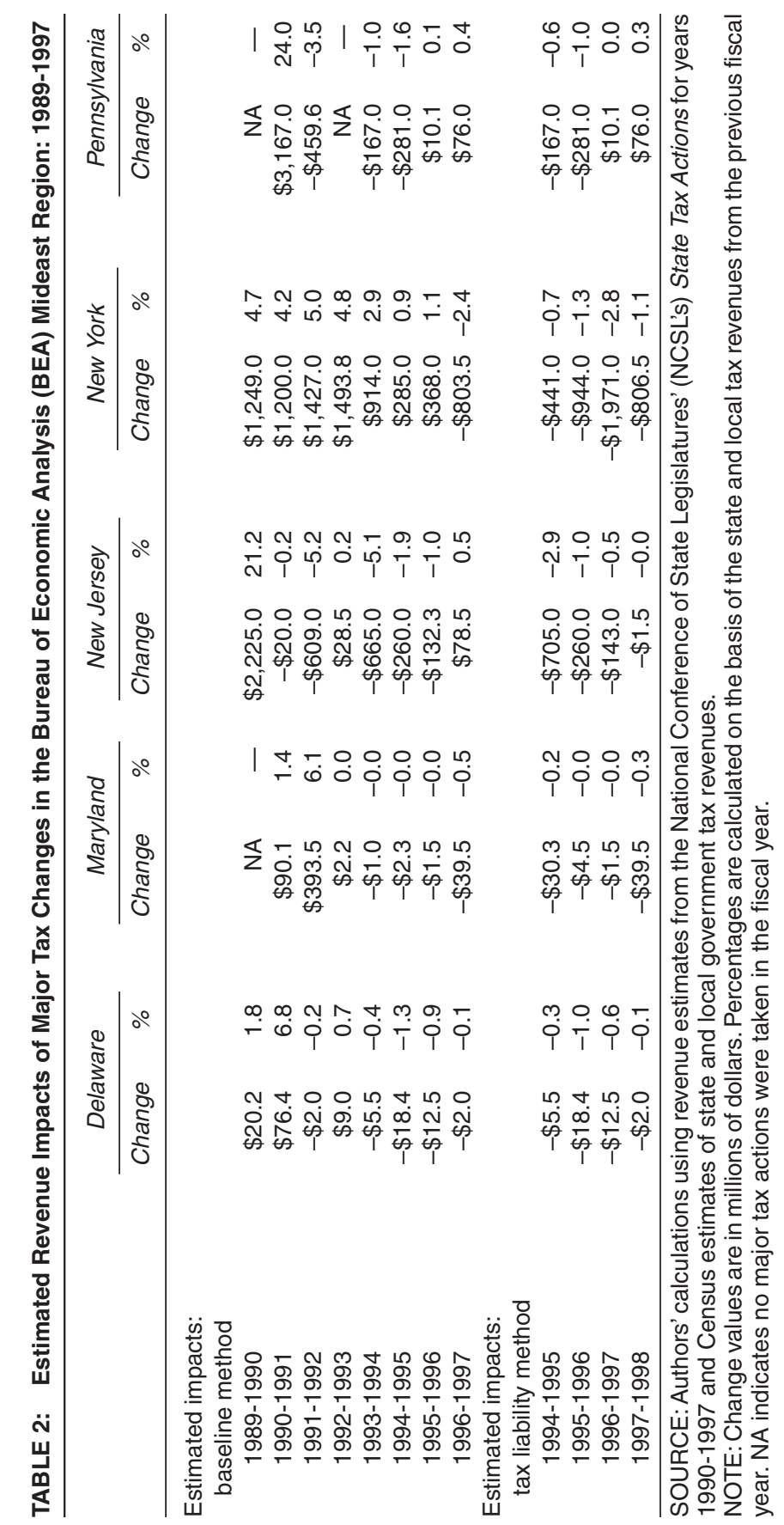


Our background investigation supports two essential claims about the New Jersey tax cuts. First, like a "natural experiment," they were instituted independently of factors specific to the state's economic growth. Second, they represented a significant departure from the tax regimes of states in the same economic region. New Jersey's tax cuts were substantially larger and more frequent than those in the rest of the Mideast region, with the possible exception of New York. The subsequent empirical analysis addresses this ambiguity by including regression specifications that separate out New York.

\section{ESTIMATION}

Given the estimation problems identified above, we employ an "event study" framework to estimate the effects of the 1994-1996 New Jersey tax cuts. ${ }^{14}$ Essentially, this approach consists of a "beforeafter" comparison of New Jersey's employment growth. For the "before" period, we choose 1989 to 1993. Employment growth during this period is compared with the period 1994-1997, which captures the cumulative effects of the 3-year period of tax cuts. We condition this comparison on employment growth in neighboring geographical areas, so that our approach may also be thought of as a variation of "difference in differences."

The Whitman tax cuts attracted attention given the size of the tax cuts and the subsequent robust economic growth. We define employment growth, EMPGT, as

$$
\text { EMPGT }_{t}=\left(\left(\frac{\text { Employment }_{t}}{\text { Employment }_{t-1}}\right)-1\right) \times 100 .
$$

As shown in Table 3, the years immediately preceding the Whitman tax cuts (1989-1993) were characterized by poor employment growth. ${ }^{15}$ Employment declined in the years 1990 through 1992, with modest annual employment growth of $0.72 \%$ in 1993 . The first year of the multiyear tax cut (1994) was also characterized by a modest employment gain of $0.97 \%$. It was followed by 3 subsequent years of robust growth of $1.54 \%, 1.27 \%$, and $2.14 \%$ a year. 
TABLE 3: Annual Growth Rates in New Jersey's Employment: 1989-1997

\begin{tabular}{cc}
\hline Year & EMPGT \\
\hline 1989 & 0.84 \\
1991 & -2.96 \\
1992 & -0.04 \\
1993 & 0.72 \\
1994 & 0.97 \\
1995 & 1.54 \\
1996 & 1.27 \\
1997 & 2.14 \\
\hline \multirow{2}{*}{ NOTE: Employment growth is defined by EMPGT } & $=\left(\left(\frac{\text { Employment }_{t}}{\text { Employment }_{t-1}}\right)-1\right) \times 100$.
\end{tabular}

An ordinary least squares (OLS) estimate of employment growth indicates that New Jersey's annual employment growth rate was 1.50 percentage points greater in the tax cut period 1994-1997 compared with the pre-tax cut period. ${ }^{16}$ When a county-level analogue is estimated using observations of employment growth in the 21 New Jersey counties and county-fixed effects, we find that New Jersey's counties grew at an annual rate that was 1.72 percentage points higher in the tax cut years compared to the pre-tax cut years. ${ }^{17}$

It is not clear that New Jersey's robust employment growth in the tax cut years differed from that of the regional economy. Given that regional economic shocks can play important roles in explaining economic growth differentials, we consider alternative geographic area definitions. ${ }^{18}$ Bureau of Economic Analysis (BEA) "Economic Regions" are defined by grouping states according to commonality of economic activity. In contrast, BEA "Economic Areas" group counties according to their degree of economic interrelatedness, as defined by commuting patterns. They consist of

one or more economic nodes - metropolitan areas or similar areas that serve as centers of economic activity-and the surrounding counties that are economically related to the nodes. (Johnson 1995, 75)

For the purposes of this study, Economic Areas are preferable to Economic Regions because counties from closely related economic areas are more likely to share a common, regional shock than counties 
TABLE 4: Distribution of Counties Across Alternative Economic Region Definitions

\begin{tabular}{|c|c|c|c|}
\hline State & $\begin{array}{c}\text { BEA Mideast } \\
\text { Region }\end{array}$ & $\begin{array}{l}\text { BEA Economic } \\
\text { Areas } 10-14^{\text {a }}\end{array}$ & $\begin{array}{c}\text { BEA Economic } \\
\text { Areas } 10 \text { and } 12^{\mathrm{a}}\end{array}$ \\
\hline Connecticut & - & 8 & 8 \\
\hline Delaware & 3 & 3 & 2 \\
\hline Maryland & 24 & 24 & 1 \\
\hline Massachusetts & 4 & 4 & \\
\hline New Jersey & 21 & 21 & 21 \\
\hline New York & 62 & 14 & 14 \\
\hline Pennsylvania & 67 & 34 & 25 \\
\hline Vermont & - & 1 & 1 \\
\hline Virginia & - & 22 & - \\
\hline West Virginia & - & 9 & - \\
\hline Total number of counties & 177 & 140 & 76 \\
\hline Total number of observations & 1,593 & 1,260 & 684 \\
\hline
\end{tabular}

a. Bureau of Economic Analysis (BEA) Economic Areas are listed in Johnson (1995).

located within the same Economic Region but different Economic Areas.

We define three relevant economic regions. The first region, the BEA Mideast region, is shown in Figure 1A. As represented in Figure $1 \mathrm{~B}$, the second region consists of the BEA Economic Areas that either directly contain New Jersey counties, or are contiguous to Economic Areas that do, or Economic Areas 10, 11, 12, 13, and 14. The third and narrowest region includes the two Economic Areas that directly contain New Jersey counties (Economic Areas 10 and 12). Table 4 reports the allocation of counties across states according to alternative definitions of economic region. Notably, the economic regions defined using BEA Economic Areas draw the great majority of their counties from the Mideast region. As a result, our earlier conclusions about the uniqueness of New Jersey's tax cuts relative to the region remain applicable when using these latter two regional definitions.

We construct a panel of observations for each of our sets of counties and estimate the fixed-effect model,

$$
E M P G T_{i t}=\alpha_{i}+\beta \text { TAXCUT }_{i t}+\gamma \text { POST93 }_{t}+\varepsilon_{i t}, \quad \quad \varepsilon_{i t} \sim N\left(0, \sigma^{2}\right),
$$

where $i=1,2, \ldots, N ; t=1989,1990, \ldots, 1997 ; \alpha_{i}$ is a county-specific fixed effect; TAXCUT is a dummy variable that takes the value 1 if the 
A

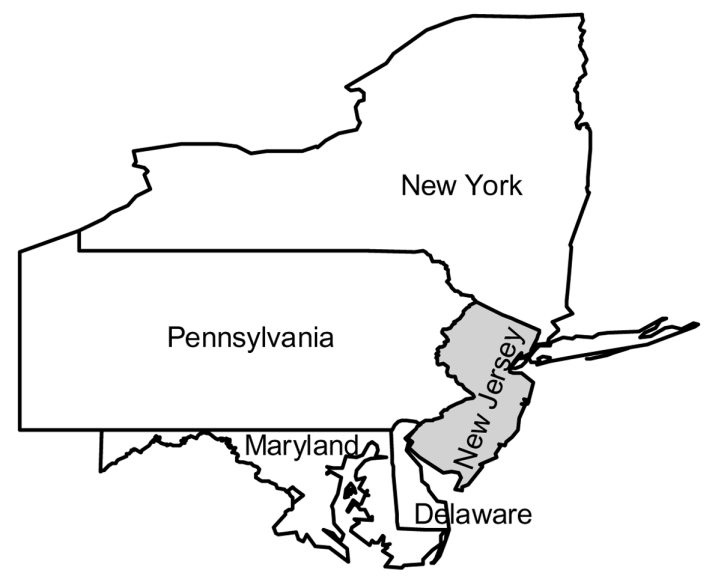

B

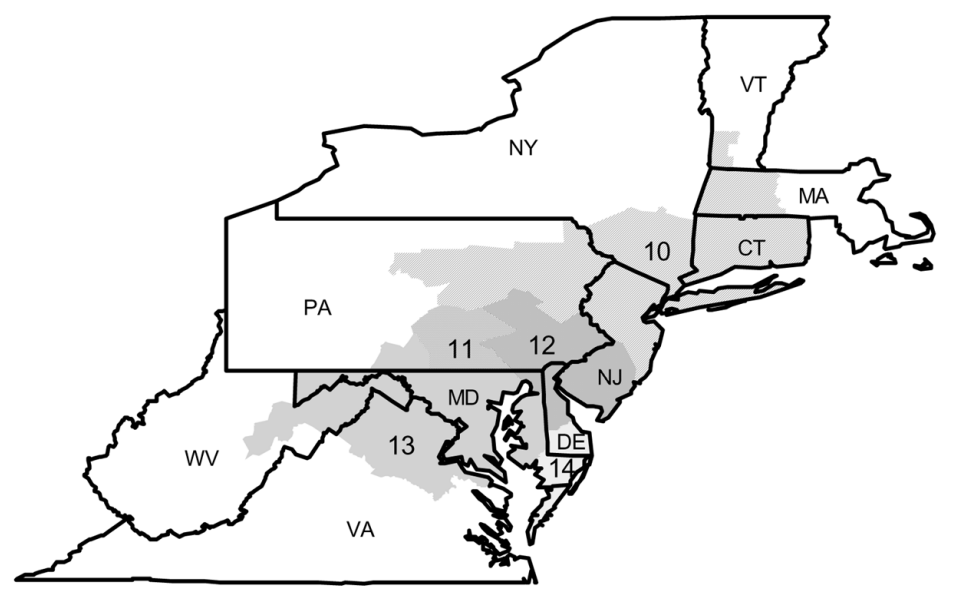

Figure 1: Geographic Area Defined by Bureau of Economic Analysis (BEA) Mideast Region (A) and Economic Areas 10 to 14 (B)

observation belongs to New Jersey during the years 1994-1997; and POST93 is a dummy variable that takes the value 1 during the years 1994-1997 and applies to all counties. Note that the total number of 
counties is given by $N=N_{1}+N_{2}+\ldots+N_{S}$, where $N_{s}$ is the number of counties in state $s$, and $S$ is the number of states. ${ }^{19}$

The dummy variable, TAXCUT, is used to model the change in New Jersey's tax regime, à la a typical difference-in-difference approach. This approach is warranted given the practical difficulties in measuring the size of tax changes. ${ }^{20}$ In addition to the problems discussed in Gold (1996), there are ambiguities in how to treat multiyear tax changes and those that are legislated retroactively, as well as in choosing between annual versus cumulative revenue estimates to assess tax impacts. ${ }^{21}$ There is also substantial measurement error associated with estimating the revenue impacts of various tax changes. ${ }^{22}$ Furthermore, estimates of the size of the tax cuts are calculated for fiscal years, whereas economic growth data, such as employment, are measured for calendar years. Consequently, a straightforward mapping of quantitative measures of tax cuts to economic growth data is not practical.

Rows 2 through 4 of Table 5 report the results of estimating equation (2) with OLS. Note that the sum of the coefficients for TAXCUT and POST93 equals the previous estimate of POST93 in row 1 that was attained using just the New Jersey counties. In other words, the original coefficient for POST93 is decomposed into a regional-specific component (POST93) and the New Jersey-specific component (TAXCUT). The coefficient on the TAXCUT variable identifies the residual growth that remains after correcting for contemporaneous regional growth.

The OLS results suggest that much of New Jersey's growth during the tax cut years was shared by counties in the surrounding region. For example, focusing first on row 2 , we estimate that annual employment growth for all counties in the Mideast region was 0.896 percentage points larger in 1994-1997 than it was in 1989-1993. The estimated TAXCUT coefficient indicates that annual employment growth in New Jersey's counties during the tax cut years was 0.821 percentage points more than what could have been expected from regional growth alone.

The estimated tax impact decreases substantially if we define the relevant region as Economic Areas 10 to 14. Including a region-specific growth component reduces the coefficient on TAXCUT to 0.389 


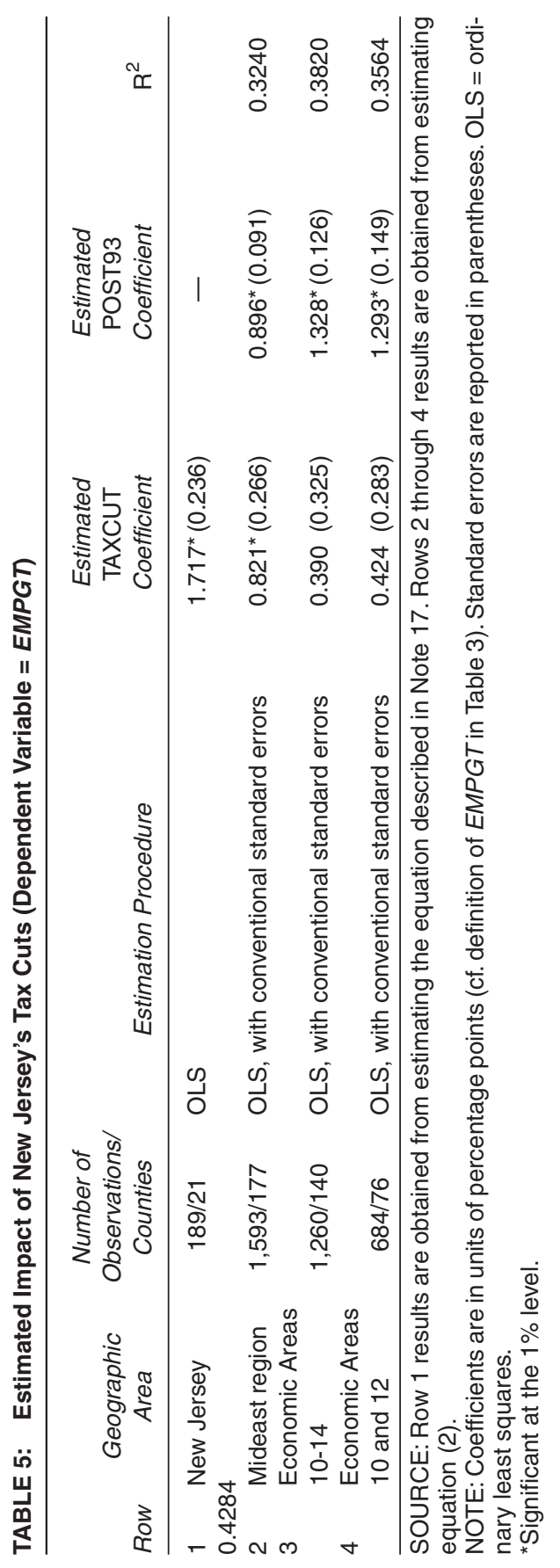


(row 3), a substantial reduction. Based on the associated $t$ value of 1.20 , the hypothesis of no increased growth cannot be rejected at conventional significance levels. The results are similar when the definition of region is narrowed to those BEA Economic Areas that directly contain New Jersey counties (Economic Areas 10 and 12). For this case, a TAXCUT coefficient of 0.424 is estimated (row 4). Although the associated standard error is somewhat smaller than the previous case, the coefficient is still insignificant at the $10 \%$ level.

It is not surprising that the results are sensitive to the regional definition used in the analysis. BEA Economic Regions are broad groups of states with a commonality of economic activity. In contrast, Economic Areas are constructed to more carefully identify areas linked by functional ties. Thus, estimates associated with Economic Areas are likely to be the most reliable measures of tax cut effects. ${ }^{23}$

The estimates presented in this section highlight the importance of accounting for overall regional growth and the sensitivity of the estimated impacts to the regional definition. The next section investigates a number of issues that may lead to better estimates, including withinstate correlation, heteroscedasticity, and autocorrelation.

\section{ESTIMATION REFINEMENTS}

Although contributing additional information and leading to more precise confidence intervals, the use of county-level data to analyze state-level policies potentially violates the assumption of independence across observations. In other words, it would be wrong to assume that the 21 counties of New Jersey represent 21 independent "natural experiments" of the impact of tax policy on economic growth. Moulton (1990, p. 334) demonstrates that "even small levels of correlation [e.g., across counties within a state] can cause the standard errors from ordinary least squares to be seriously biased downward." In addition, the panel nature of the data suggests that both groupwise heteroscedasticity and autocorrelation may be present, causing OLS to be inefficient and its standard errors to be biased.

Let $\boldsymbol{\epsilon} \sim N(0, \mathbf{V})$, where $\boldsymbol{\epsilon}$ is the vector of error terms from equation (2) above. The combination of within-state correlation, groupwise 
(state-level) heteroscedasticity, and first-order autocorrelation produces a covariance matrix $\mathbf{V}$ defined by

$$
\mathbf{V}=\Sigma \otimes \Omega,
$$

where

$$
\begin{aligned}
& \sum=\left(\begin{array}{cccc}
\Sigma_{1} & 0 & \ldots & 0 \\
0 & \Sigma_{2} & \ldots & 0 \\
\vdots & \vdots & \ddots & \vdots \\
0 & 0 & \ldots & \Sigma_{S}
\end{array}\right)_{N \times N}, \\
& \sum=\left(\begin{array}{cccc}
\sigma_{s}^{2} & \rho_{s} \sigma_{s}^{2} & \ldots & \rho_{s} \sigma_{S}^{2} \\
\rho_{s} \sigma_{s}^{2} & \sigma_{s}^{2} & \ldots & \rho_{s} \sigma_{s}^{2} \\
\vdots & \vdots & \ddots & \vdots \\
\rho_{s} \sigma_{s}^{2} & \rho_{s} \sigma_{s}^{2} & \ldots & \sigma_{s}^{2}
\end{array}\right)_{N_{s} \times N_{s}}, \\
& \Omega=\left(\begin{array}{cccc}
1 & \rho & \ldots & \rho^{T-1} \\
\rho & 1 & \ldots & \rho^{T-2} \\
\vdots & \vdots & \ddots & \vdots \\
\rho^{T-1} & \rho^{T-2} & \ldots & 1
\end{array}\right)_{T \times T},
\end{aligned}
$$

and where $\rho_{s}$ is the correlation of the error terms between counties from the same state $s, \sigma_{s}^{2}$ is the variance of the error term for counties (observations) from state $s$, and $\rho$ is a common $\operatorname{AR}(1)$ parameter, assuming that the observations are ordered first by state, then by county, and then by time. This model is easily seen to be a variation of the widely used Park model (Park 1967; Kmenta 1986). ${ }^{24}$

We proceed by obtaining consistent estimates of the elements of $\mathbf{V}$, which in turn enables feasible generalized least squares (FGLS) estimation of the model. The benefit of FGLS is that it produces coefficient estimates that are asymptotically efficient. However, Monte Carlo analysis of the Park model by Beck and Katz (1995) suggests that FGLS may produce standard errors that are substantially downwardly biased in finite samples. In contrast, they report that OLS standard errors, appropriately corrected for $\mathbf{V}$, are likely to be more reliable. As a result, we report both OLS with corrected standard errors and FGLS results.

Table 6 reports the results of reestimating equation (2), first using OLS where the standard errors are corrected for the error structure of equation (3), then using FGLS. ${ }^{25}$ Referring to rows 1 and 2 of Table 6, we see that the corrected standard errors are approximately three 


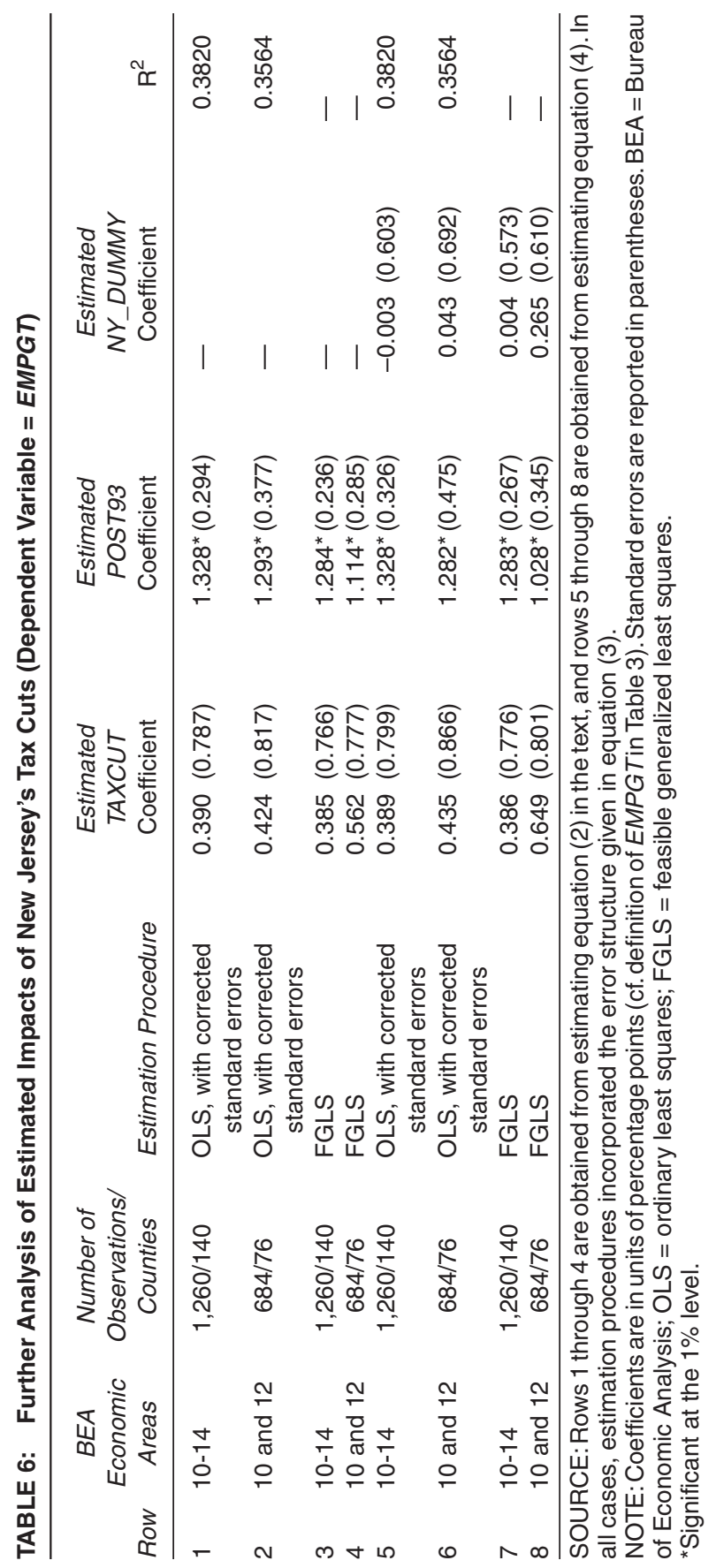


times larger than the biased standard errors produced by OLS. Virtually all of this bias can be attributed to the allowance for within-state correlation. This result is similar to that reported by Moulton (1990) and virtually identical to Duggan (2000), who performs an empirical analysis conceptually similar to ours.

Despite the dramatic change in the size of the standard errors, the conclusions from the original OLS analysis remain the same: The coefficient for the dummy variable designed to capture unaccounted, regionwide growth during 1994-1997 (POST93) is still significant at the $1 \%$ level. The coefficient for the dummy variable designed to measure New Jersey-specific growth during the tax cut years (TAXCUT) is still insignificant, with associated $p$ values now in the $60 \%$ range. The FGLS results reported in rows 3 and 4 likewise support these conclusions.

There remains one more estimation concern. We concluded earlier that New Jersey's tax cuts were substantially larger and more frequent than those of other states in the region, with the possible exception of New York. We now want to allow for "the possible exception of New York." To do that, we construct a dummy variable, $N Y \_D U M M Y$, which takes the value 1 if the observation is located in the state of New York and occurs in the time period 1994-1997. The resulting specification is given by equation (4):

$$
E M P G T_{i t}=\alpha_{i}+\beta \text { TAXCUT }_{i t}+\gamma \text { POST93 }_{t}+\delta N Y_{-} D U M M Y_{i t}+\varepsilon_{i t} .
$$

Rows 5 through 8 report the results of estimating this equation first with OLS (with corrected standard errors), then with FGLS. The $N Y \_D U M M Y$ coefficient is highly insignificant in each of the four regressions. Overall, the results concerning New Jersey's economic growth are little changed from above. (Although it is true that the FGLS coefficient for the TAXCUT coefficient is estimated to be larger when using the region defined by BEA Economic Areas 10 and 12 [row 8], the point estimate of 0.649 lies less than a standard deviation [0.801] from zero and has an associated $p$ value of .42.)

If we take the averages of the eight sets of coefficients reported in Table 6, we see that approximately three fourths of New Jersey's increased economic growth in the $1994-1997$ period was shared by counties outside the state but within the same economic region. The 

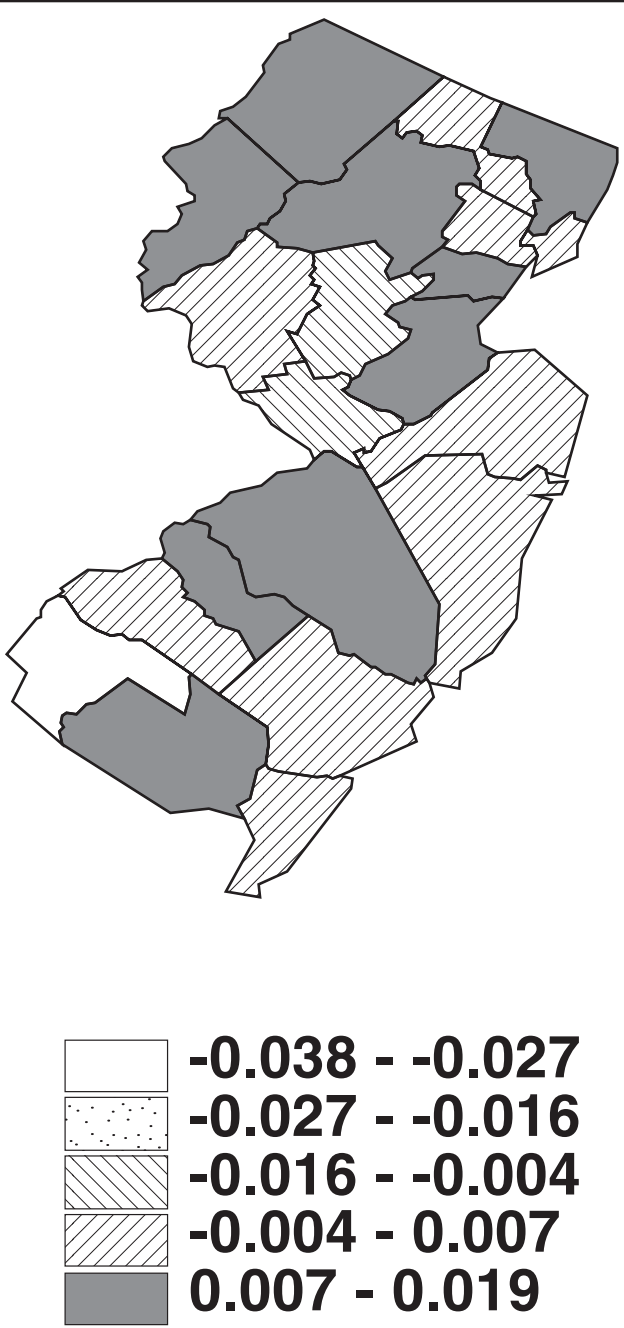

Figure 2: Individual TAXCUT Estimates for Each of New Jersey's 21 Counties NOTE: This figure represents estimated coefficients of individual TAXCUT dummy variables for the respective counties. Estimates are obtained using the ordinary least squares (OLS) model of equation (3) with TAXCUT dummy variables for each of New Jersey's 21 counties.

residual growth specific to New Jersey was not statistically significant: The $p$ values associated with the TAXCUT coefficient were larger than $40 \%$ in each of the eight regressions reported in Table 6. 
As a final check for any tax cut effects, we specify the OLS model of equation (2) with individual TAXCUT dummy variables for New Jersey's 21 counties. This specification allows us to estimate a separate tax cut effect for each New Jersey county. Although we do not report the full regression here, the individual impacts are represented in Figure $2 .{ }^{26}$ As the figure indicates, individual effects vary widely. Four of the 21 effects are estimated to be negative. None of the 21 effects is individually significant, and we cannot reject the joint hypothesis that all of the respective TAXCUT coefficients are equal to zero.

To summarize, our analysis set out to determine whether employment growth in New Jersey during 1994-1997 differed from employment growth in other areas within the same economic region. Our conclusion - robust across a wide variety of estimation procedures-is that it did not. Although New Jersey experienced strong growth during this period, so did the economies of the neighboring Economic Areas.

An alternative interpretation of our results is that perhaps New Jersey's tax cuts were effective in stimulating employment growth and that this growth "radiated" outward, stimulating growth in neighboring Economic Areas. This interpretation could also explain why we do not observe much difference between New Jersey and the surrounding Economic Areas.

If the alternative explanation were valid, however, one would expect to see the difference decreasing as one moved closer to New Jersey. Accordingly, the TAXCUT coefficient should be smaller when using BEA Economic Areas 10 and 12 (those that directly include New Jersey) than when using BEA Economic Areas 10 through 14. In fact, the opposite is true. A comparison of the odd rows with the even rows in Table 6 shows that the employment growth difference between New Jersey and its surrounding area gets larger, not smaller, when one restricts the analysis to the counties from Economic Areas that are closest to New Jersey.

Finally, a potential criticism of our study is that it adopts the framework of a "natural experiment" and assumes that New Jersey's tax cuts can be modeled as an exogenous experiment in state policy. In fact, however, to the extent that this criticism is valid, it only strengthens our conclusion. A positive correlation between economic growth and 
the adoption and continuance of New Jersey's tax cut program would cause the TAXCUT coefficient to be positively biased. This would make it more likely that we would find the residual growth specific to New Jersey to be statistically significant. The fact that we do not find statistical significance, even given a possible positive bias, makes our empirical findings even stronger.

\section{CONCLUSION}

New Jersey has two characteristics that make it an interesting case study for analyzing the impact of a large, state-level personal income tax cut. First, it can be argued that the 1994-1996 New Jersey tax cuts were driven by factors exogenous to the state economy (i.e., the Whitman effect), making it a good candidate for a "natural experiment." Second, it is a state that is frequently identified as a "role model" for policy makers contemplating tax cuts for their states.

Although New Jersey experienced substantial employment growth during the period 1994-1997, we conclude that most of this growth cannot be attributed to the tax cuts. Robust employment growth during this period was not unique to New Jersey. It is important to note, however, that our analysis is concerned with measuring the short-term impact of state-level tax policy. We do not address the issue of longterm impact, which raises a different set of econometric and specification issues.

An additional contribution of this study is that it introduces a number of empirical innovations in its study of state tax policy. It demonstrates the benefits of using county-level data while also identifying the econometric issues that arise when the analysis of state policies is moved to the county level. Furthermore, it highlights the role that BEA Economic Areas can play in controlling for unobserved regional shocks. The potential impact of spatial autocorrelation may also be important, though we leave this to future research.

As for the general question of the benefits of cutting taxes, we believe that the main lessons from our analysis of the New Jersey model do not provide support for those who promote tax-cutting policies to stimulate growth. However, we also find no evidence to indicate that 
the Whitman tax cuts hurt economic growth. This reinforces the general consensus among academics that the primary focus of state-level tax and expenditure debates should be the relative merits of public versus private spending and not the impact of these policies on shortrun aggregate economic activity.

\section{NOTES}

1. A similar conclusion has been found in the empirical literature addressing the more general relationship between government activities and economic growth (Poot 2000).

2. In contrast, Miller and Russek (1997) find a negative relationship between taxes and economic growth, even when tax revenues are used to finance public services.

3. Wasylenko $(1997,38)$ characterizes the results as "not very reliable," and Bartik (1997, 67) suggests that the results are "quite fragile." McGuire $(1992,458)$ concludes "that the effects of state and local tax policy are so uncertain that concern over this issue should not be a driving force in general policy decisions."

4. Michigan is also prominently cited for its large tax cuts during the Engler administration. However, Michigan makes a poor case study because its economy is heavily focused on a single industry (automobiles) that is driven primarily by developments in the national economy. Besley and Case (2000) discuss necessary conditions for a policy variable to be employed as an exogenous explanatory variable in cross-sectional analyses of policy incidence.

5. This is the approach suggested by Bartik (1997).

6. The political affiliations of the governors are listed in American Political Leaders, 1789 2000 (Congressional Quarterly, Inc. 2000). Whitman was elected governor of New Jersey in 1993.

7. According to Nelson (2000), the imposition of tax policy changes during the first year of a governor's term is not unusual.

8. In fact, "Republican Christie Whitman ... had made opposition to [Democratic incumbent governor] Florio's tax policies the hallmark of her dramatic run against [Senator] Bill Bradley in 1990" (Mullaney 1994, 267).

9. The Mideast region, as defined by the Bureau of Economic Analysis (BEA), includes Delaware, Maryland, New Jersey, New York, and Pennsylvania. Although the District of Columbia is also included, we restrict our discussion to the five states.

10. The National Conference of State Legislatures (NCSL) State Tax Actions provides yearly summaries of legislative actions taken by states and estimates of corresponding revenue impacts. All of the Mideast states legislated changes in various different taxes during the period. A summary is available from the authors by request.

11. The New York figures are misleading in this calculation due to the implementation of health care provider taxes that may be partially or even completely returned to providers through the Medicaid leveraging schemes. See Reed and Rogers (2000) for a discussion of measurement errors associated with Medicaid schemes and other idiosyncrasies associated with cross-state revenue comparisons.

12. The NCSL classifies tax changes as major if they are at least $1 \%$ of state tax revenues in the previous fiscal year. 
13. Tax liability measures of the size of tax changes are not available for years prior to 1994.

14. Surveys of event studies in economics and finance are given by MacKinlay (1997) and Lamdin (2001).

15. Employment data are from the Regional Economic Information Systems 1969-1997 series, produced by the Bureau of Economic Analysis.

16. The simple model includes a constant, a dummy variable taking the value 1 during the years 1994-1997, and the usual assumptions concerning the error terms.

17. The estimation equation is $E M G T_{i t}=\alpha_{i}+\beta P O S T 93_{t}+\varepsilon_{i t}, \varepsilon_{i t} \sim N(0, \sigma), i=1,2, \ldots, 21, t=$ $1989,1990, \ldots, 1997$, and POST93 $_{t}=1$ if $t>1993$.

18. For example, Carlino and DeFina (1998) show that U.S. regions have differential responses to unexpected monetary policy changes.

19. The total number of observations is $N \times T$, where $T$ is the number of years in the panel.

20. Of course, representing tax changes with a series of dummy variables raises concerns that the dummy variables measure the influence of factors other than the tax changes.

21. Note from Table 1 that the $1994 \mathrm{New}$ Jersey tax cuts were effective retroactively, so that they had revenue impacts during the same fiscal year in which they were adopted.

22. For example, the estimated sizes of New Jersey's tax cuts reported in Table 2, obtained from NCSL State Tax Action publications, differ substantially from those reported in Table 1, obtained from the Office of Tax Analysis, Department of Treasury, State of New Jersey (1998). Various factors cause the deviations in estimates. The NCSL estimates are obtained from surveys of legislative staff, which inquire about major legislative actions in the year based on the previous year's revenues. The tax office uses the current-year revenue estimates and includes all tax law changes affecting revenue during the year.

23. Another issue concerns the potential effects of spillovers from New Jersey tax cuts to the neighboring counties or in the opposite direction. Following yardstick competition models, the New Jersey tax cuts may have played a role in instigating the subsequent tax changes in New York and Pennsylvania. This would cause the estimates of the tax cut impacts using the regional subunits to be biased downward. However, as discussed before, the New York tax cuts were essentially delays of legislated tax cuts from before 1990. The Pennsylvania tax cuts were more targeted toward businesses and lower income taxpayers. Thus, it is not clear that yardstick competition was the major factor in this case. On the other hand, spillovers from New York and Philadelphia to New Jersey counties would bias estimated impacts upward when using the Mideast region in the analysis.

24. This specification can be rewritten as $Y_{t}=\beta_{0}+\beta_{1} X_{t}+\mu_{t}$, where $\mu_{t}=\rho \mu_{t-1}+\varepsilon_{t}$. Substituting for $\mu_{t}$ and solving gives $Y_{t}=\left(\beta_{0}-\rho \beta_{0}\right)+\beta_{1} X_{t}+\rho Y_{t-1}-\rho \beta_{1} X_{t-1}+\varepsilon_{t}$. Thus, our specification is tantamount to estimating $Y_{t}$ using a lagged dependent variable.

25. The SAS/IML program used to generate the estimates in Table 6 is available from the authors upon request.

26. The regression underlying these estimates used counties from Economic Areas 10 through 14 .

\section{REFERENCES}

Bartik, Timothy J. 1991. Who benefits from state and local economic development policies? Kalamazoo, MI: W. E. Upjohn Institute for Employment Research. 
1997. Discussion of Wasylenko's and Fisher's reviews. New England Economic Review, March-April, 67-71.

Beck, Nathaniel, and Jonathan Katz. 1995. What to do (and not to do) with time-series crosssection data. American Political Science Review 89:634-47.

Becsi, Zolt. 1996. Do state and local taxes affect relative state growth? Federal Reserve Bank of Atlanta Economic Review 81:18-36.

Besley, Timothy, and Anne Case. 1995. Incumbent behavior: Vote-seeking, tax-setting, and yardstick competition. American Economic Review 85:25-45.

- 2000. Unnatural experiments? Estimating the incidence of endogenous policies. Economic Journal 110:672-94.

Carlino, Gerald A., and Robert F. DeFina. 1998. The differential regional effects of monetary policy. Review of Economics and Statistics 80:572-87.

Carroll, Robert, and Michael Wasylenko. 1994. Do state business climates still matter? Evidence of a structural change. National Tax Journal 7:19-37.

Case, Anne. 1993. Interstate tax competition after TRA85. Journal of Policy Analysis and Management 12:136-48.

Congressional Quarterly, Inc. 2000. American political leaders, 1789-2000. Washington, DC: Congressional Quarterly Press.

Duggan, Mark. 2000. More guns, more crime. NBER Working Paper Series, Working Paper 7967, National Bureau of Economic Research, Cambridge, MA.

Garfield, Reed. 1996. Tax cuts and balanced budgets: A tour of Lansing and Trenton. Mimeo, Joint Economic Committee Report.

Gold, Steven D. 1996. State tax cuts of 1995: Is something new afoot? Public Budgeting and Finance 16:3-22.

Helms, L. Jay. 1985. The effect of state and local taxes on economic growth: A time series-cross section analysis. Review of Economics and Statistics 67:574-82.

Johnson, Kenneth. 1995. Redefinition of the BEA economic areas. Survey of Current Business 75:75-81.

Kmenta, Jan. 1986. Elements of econometrics. 2nd ed. New York: Macmillan.

Lamdin, Douglas J. 2001. Implementing and interpreting event studies of regulatory changes. Journal of Economics and Business 53:171-83.

Lynch, Robert. 1996. Do state and local tax incentives work? Washington, DC: Economic Policy Institute.

MacKinlay, A. Craig. 1997. Event studies in economics and finance. Journal of Economic Literature 35:13-39.

McGuire, Therese. 1992. Review of "Who benefits from state and local economic development policies?" National Tax Journal 45:457-59.

Miller, Stephen M., and Frank S. Russek. 1997. Fiscal structures and economic growth at the state and local level. Public Finance Review 25:213-37.

Mofidi, Alaeddin, and Joe A. Stone. 1990. Do state and local taxes affect economic growth? Review of Economics and Statistics 72:686-91.

Moore, Stephen, and Dean Stansel. 1996. Tax cuts and balanced budgets: Lessons from the states. Cato Fact Sheet, Cato Institute, Washington, DC.

Moulton, Brent R. 1990. An illustration of a pitfall in estimating the effects of aggregate variables on micro units. Review of Economics and Statistics 72:334-38.

Mullaney, Marie Marmo. 1994. Biographical directory of the governors of the United States, 1988-1994. Westport, CT: Meckler.

Nelson, Michael A. 2000. Electoral cycles and the politics of state tax policy. Public Finance Review 28:540-60. 
Office of Tax Analysis, Department of Treasury, State of New Jersey. 1998. Governor Whitman's major tax reductions: FY94-FY99 (\$M). Mimeo.

Park, R. 1967. Efficient estimation of a system of regression equations when disturbances are both serially and contemporaneously correlated. Journal of the American Statistical Association 62:500-9.

Phillips, Joseph, and Ernest Gross. 1995. The effect of state and local taxes on economic development: A meta-analysis. Southern Economic Journal 62:320-33.

Poot, Jacques. 2000. A synthesis of empirical research on the impact of government on long-run growth. Growth and Change 31:516-46.

Reed, Robert W., and Cynthia L. Rogers. 2000. Measurement error and endogeneity in studies of state tax policy and economic growth. Mimeo, University of Oklahoma.

Tannenwald, Robert. 1996. State business tax climate: How should it be measured and how important is it? New England Economic Review, January-February, 23-38.

Wasylenko, Michael. 1997. Taxation and economic development: The state of the economic literature. New England Economic Review, March-April, 37-52.

W. Robert Reed is a professor in the Department of Economics at the University of Oklahoma, Norman.

Cynthia L. Rogers is an associate professor in the Department of Economics at the University of Oklahoma, Norman 